\title{
Refractured Well Selection for Multicriteria Group Decision Making by Integrating Fuzzy AHP with Fuzzy TOPSIS Based on Interval-Typed Fuzzy Numbers
}

\author{
Tiejun Li, ${ }^{1,2}$ Jianhua Jin, ${ }^{1,2,3}$ and Chunquan $\mathrm{Li}^{1,2}$ \\ ${ }^{1}$ State Key Laboratory of Oil and Gas Reservoir Geology and Exploitation, Southwest Petroleum University, \\ Chengdu 610500, China \\ ${ }^{2}$ College of Sciences, Southwest Petroleum University, Chengdu 610500, China \\ ${ }^{3}$ College of Mathematics and Econometrics, Hunan University, Changsha 410082, China
}

Correspondence should be addressed to Jianhua Jin, jjh2006ok@yahoo.com.cn

Received 21 March 2012; Revised 18 June 2012; Accepted 19 June 2012

Academic Editor: Reinaldo M. Palhares

Copyright ( 2012 Tiejun Li et al. This is an open access article distributed under the Creative Commons Attribution License, which permits unrestricted use, distribution, and reproduction in any medium, provided the original work is properly cited.

\begin{abstract}
Multicriteria group decision making (MCGDM) research has rapidly been developed and become a hot topic for solving complex decision problems. Because of incomplete or non-obtainable information, the refractured well-selection problem often exists in complex and vague conditions that the relative importance of the criteria and the impacts of the alternatives on these criteria are difficult to determine precisely. This paper presents a new model for MCGDM by integrating fuzzy analytic hierarchy process (AHP) with fuzzy TOPSIS based on interval-typed fuzzy numbers, to help group decision makers for well-selection during refracturing treatment. The fuzzy AHP is used to analyze the structure of the selection problem and to determine weights of the criteria with triangular fuzzy numbers, and fuzzy TOPSIS with interval-typed triangular fuzzy numbers is proposed to determine final ranking for all the alternatives. Furthermore, the algorithm allows finding the best alternatives. The feasibility of the proposed methodology is also demonstrated by the application of refractured well-selection problem and the method will provide a more effective decision-making tool for MCGDM problems.
\end{abstract}

\section{Introduction}

With the rapid development of economic and technology, the theories and method of multicriteria decision-making $(\mathrm{MCDM})$ problems $[1,2]$ have been extensively applied to various areas such as management sciences [3, 4], operation research [5], project selection [6], and economic evaluation [7]. The goal of decision-making process is to select a finite number of alternatives generally characterized by multiple conflicting criteria. Great achievements have 
been made to the development of several MCDM approaches in modern decision science [1, 2, 6, 8-14]. Guitouni and Martel [10] stated that the aggregation of the alternative evaluations expressed according to different dimensions should imply some kind of compensation [15]. To choose an appropriate multicriteria decision aid method is to choose a kind of compensation logic. One of these techniques known as technique for order preference by similarity to ideal solution (TOPSIS) [16], developed by Hwang and Yoon [2], is a technique to evaluate the performance of alternatives through the similarity with the ideal solution. In this technique, the best alternative should have the shortest distance from the positive ideal solution and the farthest distance from the negative ideal solution. The positive ideal solution is one that maximizes the benefit criteria and minimizes the cost criteria. The negative ideal solution is one that maximizes the cost criteria and minimizes the benefit criteria. In summary, the positive ideal solution is composed of all best values attainable of criteria, and the negative ideal solution consists of all the worst values attainable of criteria. In addition, the ranking of all the alternatives is presented in decreasing order.

In the process of well selection with refracturing, a major issue is to evaluate all the chosen alternatives with respect to various criteria and to determine the relative importance of these criteria. These criteria usually conflict with each other and are incommensurable; there may be no solution satisfying all the criteria simultaneously. Moreover, because of the complexity of objective things and incomplete information, decision makers' judgments including preferences are often vague and cannot estimate their preference with an exact value. Also, different decision makers have different knowledge about these alternatives and criteria. Therefore, the refractured well selection belongs to a multicriteria decision-making problem $[1,2]$ which involves both quantitative and qualitative criteria with various kinds of uncertainties such as ignorance, interval data, and fuzziness.

In order to handle uncertainties in an effective manner, Zadeh [17] developed the theory of fuzzy sets and fuzzy logic and utilized the theory to model uncertainty or lack of knowledge successfully when applied to a variety of problems in science and engineering. Bellman and Zadeh [18] were the first to introduce the theory of fuzzy sets in problems of multicriteria decision-making as an effective approach to treat vagueness, lack of knowledge, and ambiguity inherent in the human decision-making process. Recently, Chen [19] extended the concept of TOPSIS to develop a methodology for solving multicriteria group decision making problems in fuzzy environment. Jahanshahloo et al. [20] proposed an algorithmic method to extend TOPSIS for decision-making problems with interval data. Baležentienè and Klimas [21] used the TOPSIS method with interval data to to evaluate the effectiveness and optimal rate of humic fertilizer on various impact patterns. When considering the situations that decision makers cannot reach an agreement sometimes on the method of defining linguistic variables based on the fuzzy sets, Ashtiani et al. [8] presented an interval-valued fuzzy TOPSIS method to solve the management selection application of MCDM problems. Ye [5] extended the TOPSIS method with interval-valued intuitionistic fuzzy numbers to solve virtual enterprise partner selection. Wei-guo and Hong [22] extended the TOPSIS framework of multiattribute individual decision-making to group decision-making situations by introducing the concepts of group positive ideal and group negative ideal solutions. In their method, a relative closeness to the group positive ideal solution was defined to determine the ranking order of all alternatives by calculating the distances to both the group positive ideal and group negative ideal solutions simultaneously. However, the framework proposed by Wei-guo and Hong may present limitations because the personal judgments were represented by numerical values in the traditional formulation of TOPSIS. Afterwards, Krohling and Campanharo [23] proposed a fuzzy TOPSIS for group decision making to 
evaluate the ratings of response alternatives to a simulated oil spill and to do research for finding out the best combat responses in case of accidents with oil spill in the sea. Baležentienè and Užupis [4] applied the fuzzy TOPSIS method for group decision making to evaluate fertilizing management alternatives in order to investigate mitigation of greenhouse gas emissions and maximization yield indices in agriculture.

The analytic hierarchy process (AHP) is another important MCDM approach, which was originally proposed by Saaty [24]. The AHP has been widely used by both researchers and practitioners. For instance, Dağdeviren and Yüksel [25] developed a fuzzy AHP model for behavior-based safety management. Miri lavasani et al. [26] utilized the analytical hierarchy process to estimate weights required for grouping noncommensurate risk sources in oil and gas offshore wells. Amiri [6] used the AHP and fuzzy TOPSIS methods to tackle project selection problems, who stressed that calculation of the criteria weights was important in fuzzy TOPSIS and they could change the ranking for some projects in application. Ju and Wang [27] developed a method of incorporating DS/AHP with extended TOPSIS to select suitable emergency alternatives under group decision makers. Comparing AHP and fuzzy AHP, Saaty and Tran [28] stated the invalidity of fuzzifying numerical judgments indiscriminately in the AHP. They stressed that validity is the goal in decision making and fuzzification does not necessarily improve the numerical value of a solution in those situations when the true value is already known by other means and is being estimated by a numerical process that represents judgments of involved participants, whether well or poorly informed. So it is suggested that fuzzy AHP is a preferred techniques in decision making until it is validated effectively. Then Sun [29] explored a performance evaluation model by integrating fuzzy AHP and fuzzy TOPSIS methods based on triangular fuzzy numbers. Gumus [30] handled the evaluation of hazardous waste transportation firms problem by using a two-step fuzzy-AHP and TOPSIS methodology, where the usage of fuzzyAHP weights in TOPSIS made the application more realistic and reliable. Torfi et al. [31] proposed a fuzzy multicriteria decision-making approach, combining fuzzy AHP with fuzzy TOPSIS, to evaluate the alternative options in respect to the user's preference orders when the performance ratings are vague and imprecise. Also, taking triangular fuzzy numbers as truth values of performance ratings, Büyüközkan and Cifci [32] used a combined fuzzy AHP and fuzzy TOPSIS technique to evaluate a set of hospital website alternatives in order to search for the best qualified alternative that satisfies the needs and the expectations of customers.

Considering the fact that interval-valued fuzzy numbers are more general and better to express incomplete and vague information [33-36], we try to propose a new model for multicriteria group decision-making problems by integrating fuzzy AHP with fuzzy TOPSIS in the basis of interval-typed fuzzy numbers in this paper, where the interval-typed fuzzy numbers can be regarded as a generalization of interval-valued fuzzy numbers, and the positive and negative ideal solutions are expressed by interval-typed fuzzy numbers. In addition, the algorithm is presented and applied to evaluate well selection for refracturing. The rest of the paper is organized as follows: Section 2 describes some basic concepts and the fuzzy-AHP technique. Section 3 develops a fuzzy TOPSIS for group decision making to deal with preference of the decision makers, where the decision matrix consists of intervaltyped triangular fuzzy numbers and the weights of criteria are determined by the fuzzy AHP based on triangular fuzzy numbers. Section 4 introduces the well selection for fracturing. In Section 5, the proposed method is applied to solve the refractured well-selection problem. And the practical results show that the method is of great feasibility and reliability. Finally, conclusions and directions for future work are presented in Section 6. 


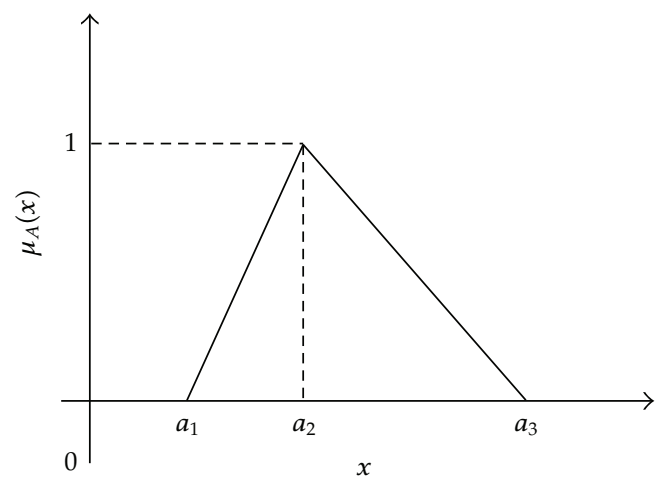

Figure 1: A triangular fuzzy number $A$.

\section{Some Basic Concepts and the Fuzzy AHP Method}

\subsection{Some Basic Concepts}

We first give some basic concepts to be used within this paper.

Definition 2.1. A triangular fuzzy number $A$ is defined as a triplet $\left(a_{1}, a_{2}, a_{3}\right)$ shown in Figure 1. The membership function $\mu_{A}(x)$ is defined as

$$
\mu_{A}(x)= \begin{cases}\frac{x-a_{1}}{a_{2}-a_{1}}, & \text { if } a_{1} \leq x \leq a_{2} \\ \frac{x-a_{3}}{a_{2}-a_{3}}, & \text { if } a_{2} \leq x \leq a_{3} \\ 0, & \text { otherwise }\end{cases}
$$

where $a_{1} \leq a_{2} \leq a_{3}$; the elements of the fuzzy numbers are real numbers, and its membership function $\mu_{A}(x)$ is the regularly and continuous convex function, showing that the membership degree to the fuzzy set; $a_{2}$ represents the value for which $\mu_{A}\left(a_{2}\right)=1$, and $a_{1}$ and $a_{3}$ are the most extreme values on the left and on the right of the fuzzy number $A$, respectively, with membership $\mu_{A}\left(a_{1}\right)=\mu_{A}\left(a_{3}\right)=0$. If $-1 \leq a_{1} \leq a_{2} \leq a_{3} \leq 1$, then $A$ is called a normalized triangular fuzzy number. If $a_{1}=a_{2}=a_{3}$, then $A$ is reduced to a real number.

Definition 2.2. Let $A=\left(a_{1}, a_{2}, a_{3}\right)$ and $B=\left(b_{1}, b_{2}, b_{3}\right)$ be two triangular fuzzy numbers. Then the operation with these fuzzy numbers are defined as follows:

(i) $A+B=\left(a_{1}+b_{1}, a_{2}+b_{2}, a_{3}+b_{3}\right)$;

(ii) $A-B=\left(a_{1}-b_{3}, a_{2}-b_{2}, a_{3}-b_{1}\right)$;

(iii) $A \times B=\left(a_{1} \cdot b_{1}, a_{2} \cdot b_{2}, a_{3} \cdot b_{3}\right)$ for $a_{i}>0, b_{i}>0$ with $i=1,2,3$;

(iv) $A / B=\left(a_{1} / b_{3}, a_{2} / b_{2}, a_{3} / b_{1}\right)$ for $a_{i}>0, b_{i}>0$ with $i=1,2,3$;

(v) $\lambda A=\left(\lambda a_{1}, \lambda a_{2}, \lambda a_{3}\right)$ for any positive $\lambda \in R$;

(vi) $A^{k}=\left(a_{1}^{k}, a_{2}^{k}, a_{3}^{k}\right)$ for $k>0, a_{1}>0, a_{2}>0$ and $a_{3}>0$. 


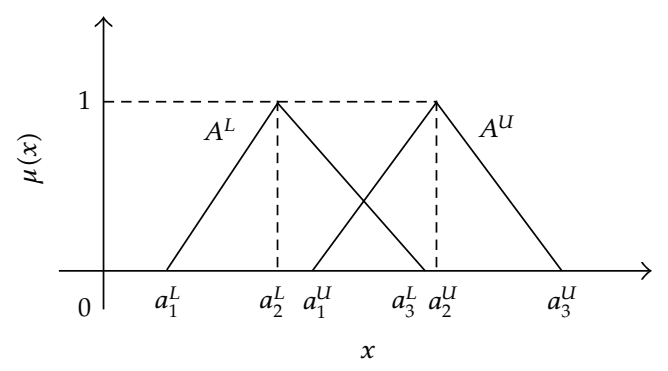

Figure 2: An interval-typed triangular fuzzy number $\left[A^{L}, A^{U}\right]$.

Definition 2.3. Let $I$ denote a finite index set, let $\left\{A_{i}=\left(a_{i 1}, a_{i 2}, a_{i 3}\right) \mid i \in I\right\}$ be a family of triangular fuzzy numbers, and let $\bigvee$ and $\Lambda$ represent the supremum and infimum operator on the real set $R$, respectively. Then

$$
\bigvee_{i \in I} A_{i}=\left(\bigvee_{i \in I} a_{i 1}, \bigvee_{i \in I} a_{i 2}, \bigvee_{i \in I} a_{i 3}\right), \quad \bigwedge_{i \in I} A_{i}=\left(\bigwedge_{i \in I} a_{i 1}, \bigwedge_{i \in I} a_{i 2}, \bigwedge_{i \in I} a_{i 3}\right)
$$

Definition 2.4. Let $A=\left(a_{1}, a_{2}, a_{3}\right)$ and $B=\left(b_{1}, b_{2}, b_{3}\right)$ be two triangular fuzzy numbers. Then the distance between them is calculated by

$$
d(A, B)=\sqrt{\frac{1}{3}\left(\left(a_{1}-b_{1}\right)^{2}+\left(a_{2}-b_{2}\right)^{2}+\left(a_{3}-b_{3}\right)^{2}\right)} .
$$

The definitions of interval-valued fuzzy numbers are shown in the references $[37,38]$ for details. As a generalization, now we introduce the definition of interval-typed triangular fuzzy numbers.

Definition 2.5. An interval-typed triangular fuzzy number is a fuzzy interval $\left[A^{L}, A^{U}\right]$, shown in Figure 2, where both the lower-bound $A^{L}=\left(a_{1}^{L}, a_{2}^{L}, a_{3}^{L}\right)$ and the upper-bound $A^{U}=$ $\left(a_{1}^{U}, a_{2}^{U}, a_{3}^{U}\right)$ are triangular fuzzy numbers and $a_{2}^{L} \leq a_{2}^{U}$.

Moreover, if $-1 \leq a_{1}^{L} \leq a_{2}^{L} \leq a_{3}^{L} \leq 1$ and $-1 \leq a_{1}^{U} \leq a_{2}^{U} \leq a_{3}^{U} \leq 1$, then $\left[A^{L}, A^{U}\right]$ is called a normalized interval-typed triangular fuzzy number. If $a_{1}^{U} \leq a_{1}^{L}, a_{2}^{L}=a_{2}^{U}$ and $a_{3}^{L} \leq a_{3}^{U}$, then $\left[A^{L}, A^{U}\right]$ is called an interval-valued triangular fuzzy number. If $A^{L}=A^{U}$, then $\left[A^{L}, A^{U}\right]$ is reduced to a triangular fuzzy number. If $a_{1}^{L}=a_{2}^{L}=a_{3}^{L}$ and $a_{1}^{U}=a_{2}^{U}=a_{3}^{U}$, then $\left[A^{L}, A^{U}\right]$ is reduced to a regular interval value. Moreover, if $a_{1}^{L}=a_{2}^{L}=a_{3}^{L}=a_{1}^{U}=a_{2}^{U}=a_{3}^{U}$, then $\left[A^{L}, A^{U}\right]$ is reduced to a numerical value.

Definition 2.6. Let $\left[A^{L}, A^{U}\right]$ and $\left[B^{L}, B^{U}\right]$ be two interval-typed triangular fuzzy numbers. Then the operations with them are defined as follows:

(i) $\left[A^{L}, A^{U}\right]+\left[B^{L}, B^{U}\right]=\left[A^{L}+B^{L}, A^{U}+B^{U}\right]$;

(ii) $\left[A^{L}, A^{U}\right]-\left[B^{L}, B^{U}\right]=\left[A^{L}-B^{U}, A^{U}-B^{L}\right]$;

(iii) $\left[A^{L}, A^{U}\right] \times\left[B^{L}, B^{U}\right]=\left[\bigwedge T_{1}, \bigvee T_{1}\right]$ for $T_{1}=\left\{A^{L} \times B^{L}, A^{L} \times B^{U}, A^{U} \times B^{L}, A^{U} \times B^{U}\right\}$; 
(iv) $\left[A^{L}, A^{U}\right] /\left[B^{L}, B^{U}\right]=\left[\bigwedge T_{2}, \bigvee T_{2}\right]$ for $T_{2}=\left\{A^{L} / B^{L}, A^{L} / B^{U}, A^{U} / B^{L}, A^{U} / B^{U}\right\}$;

(v) $k\left[A^{L}, A^{U}\right]=\left[k A^{L}, k A^{U}\right]$ for $k \in R^{+}$.

Definition 2.7. Let $\left\{\left[A_{i}^{L}, A_{i}^{U}\right]\right\}_{i \in I}$ be a collection of interval-typed triangular fuzzy numbers, where $I$ denotes a finite index set. Then

$$
\begin{aligned}
& \bigvee_{i \in I}\left[A_{i}^{L}, A_{i}^{U}\right]=\left[\bigvee_{i \in I} A_{i}^{L}, \bigvee_{i \in I} A_{i}^{U}\right], \\
& \bigwedge_{i \in I}\left[A_{i}^{L}, A_{i}^{U}\right]=\left[\bigwedge_{i \in I} A_{i}^{L}, \bigwedge_{i \in I} A_{i}^{U}\right] .
\end{aligned}
$$

Definition 2.8. Let $\left[A^{L}, A^{U}\right]$ and $\left[B^{L}, B^{U}\right]$ be two interval-typed triangular fuzzy numbers. Then the distance between them is calculated by

$$
\widehat{d}\left(\left[A^{L}, A^{U}\right],\left[B^{L}, B^{U}\right]\right)=\sqrt{\frac{1}{2}\left(d\left(A^{L}, B^{L}\right)\right)^{2}+\frac{1}{2}\left(d\left(A^{U}, B^{U}\right)\right)^{2}} .
$$

According to [39], Definition 2.8 is well defined, where the computations of $d\left(A^{L}, B^{L}\right)$ and $d\left(A^{U}, B^{U}\right)$ are given by Definition 2.4.

\subsection{Fuzzy Analytical Hierarchy Process (AHP)}

Fuzzy AHP utilizes a similar framework to AHP in conducting analysis by using fuzzy ratios instead of crisp values. The approach to determine weighting factors in refractured well selection is composed of the following steps.

Step 1. Identify the factors and sub-factors to be used in the model.

Step 2. Structure the AHP model hierarchically based on the factors and sub-factors identified at Step 1. AHP model is structured such that the objective is in the first level, factors are in the second level, and the sub-factors from the second level are on the third level.

Step 3. Determine the local weights of the factors and sub-factors by using pairwise comparison matrices. The fuzzy scale regarding relative importance to measure the relative weights is given in Table 1. This scale is proposed by Kahraman et al. [40] and used for solving fuzzy decision-making problems $[40,41]$ in the literature.

For example, there are $n$ factors to the objective in the second level. Assign linguistic terms to the pairwise comparisons by asking which is the more important of each two factors. Then the matrix is constructed as follows:

$$
A=\left(\begin{array}{cccc}
a_{11} & a_{12} & \cdots & a_{1 n} \\
a_{21} & a_{22} & \cdots & a_{2 n} \\
\vdots & \vdots & \vdots & \vdots \\
a_{n 1} & a_{n 2} & \cdots & a_{n n}
\end{array}\right)
$$


Table 1: Linguistic scales for importance.

\begin{tabular}{lcc}
\hline Linguistic scales for relative importance & Triangular fuzzy scale & Triangular fuzzy reciprocal scale \\
\hline Just equal & $(1,1,1)$ & $(1,1,1)$ \\
Equally important (EI) & $(1 / 2,1,3 / 2)$ & $(2 / 3,1,2)$ \\
Weakly more important (WMI) & $(1,3 / 2,2)$ & $(1 / 2,2 / 3,1)$ \\
Strongly more important (SMI) & $(3 / 2,2,5 / 2)$ & $(2 / 5,1 / 2,2 / 3)$ \\
Very strongly more important (VSMI) & $(2,5 / 2,3)$ & $(1 / 3,2 / 5,1 / 2)$ \\
Absolutely more important (AMI) & $(5 / 2,3,7 / 2)$ & $(2 / 7,1 / 3,2 / 5)$ \\
\hline
\end{tabular}

where $a_{i j}$ is a fuzzy comparison value of factor $i$ to factor $j, a_{i i}=(1,1,1)$ with $i=1, \ldots, n$, and $a_{i j}=(1,1,1) / a_{j i}$ with $i, j=1, \ldots, n$.

Next, we use geometric mean technique $[42,43]$ to define the fuzzy geometric mean and fuzzy local weights of factors:

$$
\begin{gathered}
r_{i}=\left(a_{i 1} \times \cdots \times a_{i j} \times \cdots \times a_{i n}\right)^{1 / n}, \\
w_{i}=\frac{r_{i}}{r_{1}+\cdots+r_{i}+\cdots+r_{n}}, \quad i=1, \ldots, n,
\end{gathered}
$$

where $r_{i}$ is a geometric mean of fuzzy comparison value of factor $i$ to each factor and $w_{i}$ is the fuzzy local weight of the $i$ th factor.

Step 4. Calculate the global weights for the sub-factors. Global subfactor weights are computed by multiplying local weight of the sub-factor with the local weight of the factor to which it belongs.

\section{The Proposed Fuzzy TOPSIS with Interval-Valued Fuzzy Numbers}

Let $G=\left\{G_{1}, G_{2}, \ldots, G_{l}\right\}, A=\left\{A_{1}, A_{2}, \ldots, A_{m}\right\}$, and $C=\left\{C_{1}, C_{2}, \ldots, C_{n}\right\}$ be a set of decision makers in the group decision making, a set of alternatives, and a set of criteria, respectively. Suppose that ${ }^{k} a_{i j}=\left[{ }^{k} x_{i j}^{L},{ }^{k} x_{i j}^{U}\right]$ is the criterion value given by the decision maker $G_{k}$, where ${ }^{k} a_{i j}$ is a normalized interval-typed triangular fuzzy number for the alternative $A_{i}$ with respect to the criterion $C_{j}$ with $i=1, \ldots, m ; j=1, \ldots, n$. Let triangular fuzzy number ${ }^{k} \tilde{\omega}_{j}=$ $\left({ }^{k} \omega_{j 1},{ }^{k} \omega_{j 2},{ }^{k} \omega_{j 3}\right)$ be the $j$ th criterion weight given by the decision maker $G_{k}, j=1, \ldots, n$; $k=1, \ldots, l$. Suppose $\lambda=\left(\lambda_{1}, \lambda_{2}, \ldots, \lambda_{l}\right)$ be the weight vector of decision makers, where $0 \leq \lambda_{k} \leq 1, k=1, \ldots, l$, and $\sum_{k=1}^{l} \lambda_{k}=1$. Then we utilize the criteria weights, the decision makers' weights, and the criteria values to rank the order of the alternatives in the following steps.

Step 1. Determine the weighted vector of criteria by virtue of fuzzy AHP, which is suitable for dealing with the uncertainty associated with the mapping of human judgment to a number by natural language. The weight vectors with respect to each group decision maker are described by

$$
{ }^{k} \omega=\left({ }^{k} \widetilde{\omega_{1}},{ }^{k} \widetilde{\omega_{2}}, \ldots,{ }^{k} \widetilde{\omega_{n}}\right), \quad k=1, \ldots, l
$$


Step 2. Construct a weighted fuzzy normalized decision matrix for each decision maker as follows:

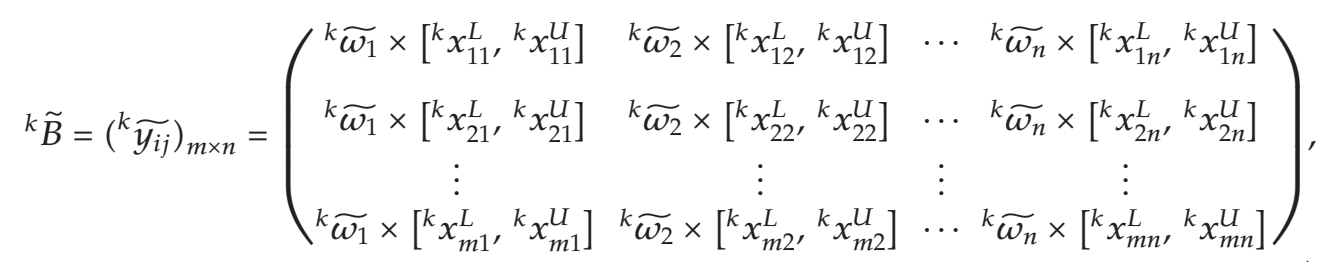

where $k=1, \ldots, l$, and the element ${ }^{k} \widetilde{y_{i j}}(i=1, \ldots, m ; j=1, \ldots, n)$ of ${ }^{k} \widetilde{B}$ can be calculated according to Definition 2.6 (iii), 2.2, and 2.3; that is,

$$
\begin{gathered}
{ }^{k} \widetilde{y_{i j}}={ }^{k} \widetilde{\omega_{j}} \times\left[{ }^{k} x_{i j}^{L},{ }^{k} x_{i j}^{U}\right]=\left[{ }^{k} \widetilde{\omega_{j}},{ }^{k} \widetilde{\omega_{j}}\right] \times\left[{ }^{k} x_{i j}^{L},{ }^{k} x_{i j}^{U}\right]=\left[{ }^{k} b_{i j}^{L},{ }^{k} b_{i j}^{U}\right], \\
{ }^{k} b_{i j}^{L}=\bigwedge\left\{{ }^{k} \widetilde{\omega_{j}} \times{ }^{k} x_{i j}^{L}{ }^{k} \widetilde{\omega_{j}} \times{ }^{k} x_{i j}^{U}\right\}, \quad{ }^{k} b_{i j}^{U}=\bigvee\left\{{ }^{k} \widetilde{\omega_{j}} \times{ }^{k} x_{i j}^{L}{ }^{k} \widetilde{\omega_{j}} \times{ }^{k} x_{i j}^{U}\right\} .
\end{gathered}
$$

Step 3. Identify the positive ideal solution ${ }^{k} S^{+}$and negative ideal solution ${ }^{k} S^{-}$for each decision maker $G_{k}(k=1, \ldots, l)$ as follows:

$$
\begin{aligned}
& { }^{k} S^{+}=\left({ }^{k} S_{1}^{+},{ }^{k} S_{2}^{+}, \ldots,{ }^{k} S_{n}^{+}\right), \\
& { }^{k} S^{-}=\left({ }^{k} S_{1}^{-},{ }^{k} S_{2}^{-}, \ldots,{ }^{k} S_{n}^{-}\right),
\end{aligned}
$$

where

$$
\begin{aligned}
& { }^{k} S_{j}^{+}= \begin{cases}\bigvee_{i \in N_{m}}{ }^{k} \widetilde{y_{i j},} & \text { if } j \in J_{1}, \\
\bigwedge_{i \in N_{m}}{ }^{k} \widetilde{y_{i j},} & \text { if } j \in J_{2},\end{cases} \\
& { }^{k} S_{j}^{-}= \begin{cases}\bigwedge_{i \in N_{m}}^{k} \widetilde{y_{i j},} & \text { if } j \in J_{1}, \\
\bigvee_{i \in N_{m}}{ }^{k} \widetilde{y_{i j},} & \text { if } j \in J_{2},\end{cases}
\end{aligned}
$$

$j=1, \ldots, n ; N_{m}=\{1, \ldots, m\}, J_{1}$ is composed of the criteria with the property that the more value of the criterion the better, and $J_{2}$ consists of the criteria with the property that the less its value, the better.

Step 4. Calculate the distances from the positive ideal solution ${ }^{k} S^{+}$and the negative ideal solution ${ }^{k} S^{-}$for each alternative $A_{i}$, respectively. The distance of alternative $A_{i}$ from the positive ideal solution of the group decision maker $G_{k},{ }^{k} d_{i}^{+}$is given by

$$
{ }^{k} d_{i}^{+}=\sum_{j=1}^{n} \widehat{d}\left({ }^{k} \widetilde{y_{i j}},{ }^{k} S_{j}^{+}\right)=\sum_{j=1}^{n} \sqrt{\frac{1}{2}\left(d\left({ }^{k}{\widetilde{y_{i j}}}^{L},{ }^{k} S_{j}^{+L}\right)\right)^{2}+\frac{1}{2}\left(d\left(k \widetilde{y_{i j}} U, k S_{j}^{+U}\right)\right)^{2}}, \quad i \in N_{m} .
$$


In a similar way, the distance of alternative $A_{i}$ from the negative ideal solution of the group decision maker $G_{k},{ }^{k} d_{i}^{-}$is given by

$$
{ }^{k} d_{i}^{-}=\sum_{j=1}^{n} \widehat{d}\left({ }^{k} \widetilde{y_{i j}},{ }^{k} S_{j}^{-}\right)=\sum_{j=1}^{n} \sqrt{\frac{1}{2}\left(d\left({ }^{k}{\widetilde{y_{i j}}}^{L},{ }^{k} S_{j}^{-L}\right)\right)^{2}+\frac{1}{2}\left(d\left(k \widetilde{y_{i j}}{ }^{U}, k S_{j}^{-U}\right)\right)^{2}}, \quad i \in N_{m}
$$

where the distance between two triangular fuzzy numbers is defined in Section 2 .

Step 5. Calculate the relative closeness for each alternative $A_{i}$ of each decision maker $G_{k}$, ${ }^{k} p\left(A_{i}\right)$ with respect to the positive ideal solution as

$$
{ }^{k} p\left(A_{i}\right)=\frac{{ }^{k} d_{i}^{-}}{{ }^{k} d_{i}^{+}+{ }^{k} d_{i}^{-}}, \quad i \in N_{m}, k=1, \ldots, l .
$$

The higher the value of ${ }^{k} p\left(A_{i}\right)$, the closer the $i$ th alternative is to the positive ideal solution for the decision maker $G_{k}$.

Next, the relative closeness matrix is constructed by

$$
\mathrm{RC}=\left(\begin{array}{cccc}
{ }^{1} p\left(A_{1}\right) & { }^{2} p\left(A_{1}\right) & \ldots & { }^{1} p\left(A_{1}\right) \\
{ }^{1} p\left(A_{2}\right) & { }^{2} p\left(A_{2}\right) & \ldots & { }^{1} p\left(A_{2}\right) \\
\vdots & \vdots & \vdots & \vdots \\
{ }^{1} p\left(A_{m}\right) & { }^{2} p\left(A_{m}\right) & \cdots & { }^{1} p\left(A_{m}\right)
\end{array}\right)
$$

And the weighted relative closeness matrix by introducing the importance weights of group decision makers into the relative closeness is presented as follows:

$$
\mathrm{WRC}=\left(\begin{array}{cccc}
\lambda_{1} \cdot{ }^{1} p\left(A_{1}\right) & \lambda_{2} \cdot{ }^{2} p\left(A_{1}\right) & \cdots & \lambda_{l} \cdot{ }^{l} p\left(A_{1}\right) \\
\lambda_{1} \cdot{ }^{1} p\left(A_{2}\right) & \lambda_{2} \cdot{ }^{2} p\left(A_{2}\right) & \cdots & \lambda_{l} \cdot{ }^{l} p\left(A_{2}\right) \\
\vdots & \vdots & \vdots & \vdots \\
\lambda_{1} \cdot{ }^{1} p\left(A_{m}\right) & \lambda_{2} \cdot{ }^{2} p\left(A_{m}\right) & \cdots & \lambda_{l} \cdot{ }^{l} p\left(A_{m}\right)
\end{array}\right)
$$

Step 6. Construct the group positive ideal solution $S_{G}^{+}$and the group negative ideal solution $S_{G^{\prime}}^{-}$, respectively, by applying the classical TOPSIS to the decision matrix in the following:

$$
\begin{aligned}
& S_{G}^{+}=\left(\widehat{S}_{G_{1}}^{+}, \widehat{S}_{G_{2}}^{+}, \ldots, \widehat{S}_{G_{l}}^{+}\right)=\left(\bigvee_{i \in N_{m}} \lambda_{1} \cdot{ }^{1} p\left(A_{i}\right), \bigvee_{i \in N_{m}} \lambda_{2} \cdot{ }^{2} p\left(A_{i}\right), \ldots, \bigvee_{i \in N_{m}} \lambda_{l} \cdot{ }^{l} p\left(A_{i}\right)\right), \\
& S_{G}^{-}=\left(\widehat{S}_{G_{1}}^{-}, \widehat{S}_{G_{2}}^{-}, \ldots, \widehat{S}_{G_{l}}^{-}\right)=\left(\bigwedge_{i \in N_{m}} \lambda_{1} \cdot{ }^{1} p\left(A_{i}\right), \bigwedge_{i \in N_{m}} \lambda_{2} \cdot{ }^{2} p\left(A_{i}\right), \ldots, \bigwedge_{i \in N_{m}} \lambda_{l} \cdot{ }^{l} p\left(A_{i}\right)\right),
\end{aligned}
$$


Step 7. Calculate to each alternative $A_{i}$ the distances from the group positive ideal solution $S_{G}^{+}$and from the group negative ideal solution $S_{G^{\prime}}^{-}$, respectively, as follows:

$$
\begin{aligned}
& d_{G_{i}}^{+}=\sqrt{\sum_{r=1}^{l}\left(\lambda_{r} \cdot{ }^{r} p\left(A_{i}\right)-\widehat{S}_{G_{r}}^{+}\right)^{2}}, \\
& d_{G_{i}}^{-}=\sqrt{\sum_{r=1}^{l}\left(\lambda_{r} \cdot{ }^{r} p\left(A_{i}\right)-\widehat{S}_{G_{r}}^{-}\right)^{2}},
\end{aligned}
$$

where $i \in N_{m}$.

Step 8. Calculate the group relative closeness $\delta_{G}$ for each alternative $A_{i}\left(i \in N_{m}\right)$ with respect to group positive ideal solution $S_{G}^{+}$as

$$
\delta_{G}\left(A_{i}\right)=\frac{d_{G_{i}}^{-}}{\left(d_{G_{i}}^{-}+d_{G_{i}}^{+}\right)} .
$$

Step 9. Rank the alternatives according to the group relative closeness. The bigger the $\delta_{G}\left(A_{i}\right)$ is, the better the alternative $i$ is, vice versa. This is the reason that the alternative having higher value $\delta_{G}\left(A_{i}\right)$ is closer to the group positive ideal solution. Therefore, the best alternatives are those that have the highest value $\delta_{G}$.

\section{Refractured Well Selection}

In the low-permeability oil and gas development process, refracturing of oil and gas wells has been extensively used and become an important measure to maintain and increase the production of more crude oil in the failure of the original crack. During refracturing treatment, several properties of oil and gas reservoir including porosity, formation pressure, and oil saturation reduce to varying degrees. Moreover, it is difficult for refractured well to ensure a certain amount of economic output. Currently, the alternative of refractured well is chosen mainly by experience. Since human judgments including preferences are often vague and imprecise and many factors affecting refractured well selection are complex and often conflict with each other, whether the desire yield is achieved after refracturing is unknown. In this paper, we try to deal with the well selection of refracturing problem by quantitative factors comprehensively and by means of fuzzy AHP and fuzzy TOPSIS. By that, we can quantificationally determine the preferred candidate well for refracturing. As an illustration, consider six wells in a certain oil field as alternatives. There are many kinds of factors affecting refracturing as follows.

\subsection{Effective Permeability $(c 1)$}

Effective permeability is one of the important parameters for evaluating reservoir, which reflects the capacity for allowing fluid to flow through the formation. If the reservoir lithology is too dense and has extremely low permeability, then the yield will not be too high due 
to the diversion capacity constraints, even if the formation pressure is higher and have larger reserves. So making refracturing measurement can greatly generate far-reaching crack, improve the reservoir flow capacity and enlarge the drainage area in order to achieve the increasing yield effect obviously.

\subsection{Reservoir Effective Thickness (c2)}

Whether the fracturing measures can be implemented is directly affected by the size of the reservoir's effective thickness. If the effective thickness is too thin, the yield through fracturing will be greatly affected.

\subsection{Porosity $(c 3)$}

For the reservoir with low porosity and poor connectivity, taking fracturing can generate crack in the formation, change pore network structure, and increase the number of connected throat to help improving conductivity.

\subsection{Water Saturation (c4)}

Water saturation, an important parameter for the calculation of reserves and recoverable reserves, directly reflects the quality of the reservoir. The higher the water saturation for well layer, the worse the yield of fractured well layer.

\subsection{Skin Factor ( $c 5)$}

Skin coefficient reflects the degree of well pollution. The higher the skin factor, the more serious the well pollution. When permeability decreased more and more seriously near the wellbore and the fluid fall into the well, the exploration value is lost because of the loss of a large amount of energy. If the conduct of fracturing removes the blocking, then both the yield and the flow condition can be effectively improved.

\subsection{Producing Pressure Drop (c6)}

The bigger the producing pressure drop, the bigger the loss of pressure induced by fluid flowing from the supply side to the bottom of well. It shows that reservoir has poor connectivity and low permeability zone. If the fracturing is conducted, then energy consumption can be reduced and low permeability zone crack is generated.

\subsection{Formation Pressure $(c 7)$}

All the oil, gas, and water contained in oil and gas layer bear certain formation pressure. Generally speaking, the deeper the reservoir, the larger the formation pressure. Most of the reservoir pressure coefficient lies between 0.7 and 1.2. The reservoir pressure, less than 0.7, is called abnormal low pressure. And the reservoir, higher than 1.2, is called abnormal high pressure. 
Table 2: Several characteristic parameters of six alternatives for refracturing.

\begin{tabular}{ccccccccc}
\hline & $\begin{array}{c}c 1 \\
\left(\times 10^{-3} \mu \mathrm{m}^{2}\right)\end{array}$ & $\begin{array}{c}c 2 \\
(\mathrm{~m})\end{array}$ & $\begin{array}{c}c 3 \\
(\%)\end{array}$ & $\begin{array}{c}c 4 \\
(\%)\end{array}$ & $c 5$ & $\begin{array}{c}c 6 \\
(\mathrm{MPa})\end{array}$ & $\begin{array}{c}c 7 \\
(\mathrm{MPa})\end{array}$ & $\begin{array}{c}c 8 \\
(\mathrm{t} / \mathrm{d})\end{array}$ \\
\hline$A_{1}$ & {$[10,11]$} & {$[17.8,20]$} & {$[5.5,6]$} & {$[49,50]$} & {$[6.48,6.5]$} & {$[8.9,9.1]$} & {$[39.6,40]$} & {$[4.12,4.18]$} \\
$A_{2}$ & {$[0.2,0.3]$} & {$[10.2,11]$} & {$[5.5,6]$} & {$[57,59]$} & {$[0.76,0.8]$} & {$[9.9,10]$} & {$[49.8,50]$} & {$[3.05,3.1]$} \\
$A_{3}$ & {$[10.8,11.2]$} & {$[9.8,10.6]$} & {$[4.8,5]$} & {$[50,51]$} & {$[11.35,12]$} & {$[12,13]$} & {$[47.5,47.8]$} & {$[4.11,4.2]$} \\
$A_{4}$ & {$[4.5,5]$} & {$[6.4,7.5]$} & {$[4.8,6]$} & {$[55,56]$} & {$[9.32,9.5]$} & {$[7,7.2]$} & {$[49.9,50]$} & {$[1.13,1.16]$} \\
$A_{5}$ & {$[12.5,13]$} & {$[3.2,4]$} & {$[6,6.5]$} & {$[58,60]$} & {$[2.25,2.5]$} & {$[15,15.5]$} & {$[49.8,50]$} & {$[3.02,3.1]$} \\
$A_{6}$ & {$[4,4.5]$} & {$[5.2,6]$} & {$[4,4.5]$} & {$[40,42]$} & {$[7.12,7.3]$} & {$[9.5,9.6]$} & {$[47.9,48]$} & {$[2,2.05]$} \\
\hline
\end{tabular}

\subsection{Oil Production Daily $(c 8)$}

Oil production is the capability logo for the well. Fracturing measures aim at choosing the wells with low permeability or production.

Table 2 presents the measured values of the alternatives with respect to the above influencing factors. Because of some incomplete and unattainable information, the result data is determined by interval data. Next we utilize the proposed approach to determine the preferred alternatives with refracturing measurement.

\section{Results and Discussion}

Firstly, suppose that the matrix $B_{1}=\left(u_{i j}\right)_{m \times n}$ consists of the interval data from Table 2, where $u_{i j}=\left[u_{i j}^{L}, u_{i j}^{U}\right]$ and $u_{i j}$ denotes the interval data from the alternative $A_{i}$ with respect to the criterion $c j, i=1, \ldots, m ; j=1, \ldots, n$. Then we calculate a normalized decision matrix $B_{2}=$ $\left(n_{i j}\right)_{m \times n}$ with $n_{i j}=\left[n_{i j}^{L}, n_{i j}^{U}\right], i=1, \ldots, m ; j=1, \ldots, n$, as follows:

$$
\begin{aligned}
& n_{i j}^{L}=\frac{x_{i j}^{L}}{\sqrt{\sum_{i=1}^{m}\left(\left(x_{i j}^{L}\right)^{2}+\left(x_{i j}^{U}\right)^{2}\right)}}, \\
& n_{i j}^{U}=\frac{x_{i j}^{U}}{\sqrt{\sum_{i=1}^{m}\left(\left(x_{i j}^{L}\right)^{2}+\left(x_{i j}^{U}\right)^{2}\right)}} .
\end{aligned}
$$

Since our field data given in Table 2 is affected by complex environment, incomplete information, and human imprecise judgments, decision makers' judgments including preferences are often vague and cannot estimate his preference with an exact value. Here, we consider that the rating of each alternative is affected by $5 \%$ of uncertainty. Therefore, the fuzzy decision matrix after normalization using interval-valued triangular fuzzy numbers is shown in Table 3.

In the process of decision making for refractured well selection, suppose that the decision makers consist of three managers from the project, two experts $\left(G_{1}\right.$ and $\left.G_{2}\right)$ from 
Table 3: A fuzzy normalized decision matrix.

\begin{tabular}{|c|c|c|}
\hline & $c 1$ & $c 2$ \\
\hline & {$[(0.3221,0.3390,0.3560),(0.3543,0.3729,0.3916)]$} & {$[(0.4625,0.4868,0.5112),(0.5197,0.5470,0.5744)]$} \\
\hline$A_{2}$ & {$[(0.0064,0.0068,0.0071),(0.0097,0.0102,0.0107)]$} & {$[(0.2650,0.2790,0.2929),(0.2858,0.3009,0.3159)]$} \\
\hline$A_{3}$ & {$[(0.3479,0.3662,0.3845),(0.3607,0.3797,0.3987)]$} & {$[(0.2546,0.2680,0.2814),(0.2754,0.2899,0.3044)]$} \\
\hline$A_{4}$ & {$[(0.1449,0.1526,0.1602),(0.1610,0.1695,0.1780)]$} & {$[(0.1663,0.1750,0.1838),(0.1949,0.2051,0.2154)]$} \\
\hline$A_{5}$ & {$[(0.4026,0.4238,0.4450),(0.4187,0.4408,0.4628)]$} & {$[(0.0831,0.0875,0.0919),(0.1039,0.1094,0.1149)]$} \\
\hline$A_{6}$ & {$[(0.1288,0.1356,0.1424),(0.1449,0.1526,0.1602)]$} & {$[(0.1351,0.1422,0.1493),(0.1559,0.1641,0.1723)]$} \\
\hline \multicolumn{2}{|r|}{ c3 } & $c 4$ \\
\hline & {$[(0.2777,0.2923,0.3069),(0.3029,0.3189,0.3348)]$} & {$[(0.2554,0.2688,0.2823),(0.2606,0.2743,0.2880)]$} \\
\hline & {$[(0.2777,0.2923,0.3069),(0.3029,0.3189,0.3348)]$} & {$[(0.2971,0.3127,0.3284),(0.3075,0.3237,0.3399)]$} \\
\hline & {$[(0.2423,0.2551,0.2678),(0.2524,0.2657,0.2790)]$} & {$[(0.2606,0.2743,0.2880),(0.2658,0.2798,0.2938)]$} \\
\hline & {$[(0.2423,0.2551,0.2678),(0.3029,0.3189,0.3348)]$} & {$[(0.2867,0.3018,0.3168),(0.2919,0.3072,0.3226)]$} \\
\hline & {$[(0.3029,0.3189,0.3348),(0.3282,0.3454,0.3627)]$} & {$[(0.3023,0.3182,0.3341),(0.3127,0.3292,0.3456)]$} \\
\hline$A_{6}$ & {$[(0.2019,0.2126,0.2232),(0.2272,0.2391,0.2511)]$} & {$[(0.2085,0.2195,0.2304),(0.2189,0.2304,0.2420)]$} \\
\hline \multicolumn{2}{|r|}{$c 5$} & $c 6$ \\
\hline & {$[(0.2413,0.2540,0.2667),(0.2421,0.2548,0.2676)]$} & {$[(0.2243,0.2361,0.2479),(0.2293,0.2414,0.2534)]$} \\
\hline & {$[(0.0283,0.0298,0.0313),(0.0298,0.0314,0.0329)]$} & {$[(0.2494,0.2626,0.2757),(0.2520,0.2652,0.2785)]$} \\
\hline & {$[(0.4227,0.4449,0.4672),(0.4469,0.4704,0.4940)]$} & {$[(0.3024,0.3183,0.3342),(0.3276,0.3448,0.3620)]$} \\
\hline & {$[(0.3471,0.3654,0.3836),(0.3538,0.3724,0.3910)]$} & {$[(0.1764,0.1857,0.1949),(0.1814,0.1910,0.2005)]$} \\
\hline & {$[(0.0838,0.0882,0.0926),(0.0931,0.0980,0.1029)]$} & {$[(0.3780,0.3978,0.4177),(0.3906,0.4111,0.4317)]$} \\
\hline & {$[(0.2652,0.2791,0.2931),(0.2719,0.2862,0.3005)]$} & {$[(0.2394,0.2520,0.2646),(0.2419,0.2546,0.2674)]$} \\
\hline \multicolumn{2}{|r|}{$c 7$} & $c 8$ \\
\hline & {$[(0.2279,0.2399,0.2518),(0.2302,0.2423,0.2544)]$} & {$[(0.3612,0.3802,0.3992),(0.3664,0.3857,0.4050)]$} \\
\hline & {$[(0.2866,0.3016,0.3167),(0.2877,0.3028,0.3180)]$} & {$[(0.2674,0.2814,0.2955),(0.2717,0.2860,0.3004)]$} \\
\hline & {$[(0.2733,0.2877,0.3021),(0.2750,0.2895,0.3040)]$} & {$[(0.3603,0.3792,0.3982),(0.3682,0.3876,0.4069)]$} \\
\hline & {$[(0.2871,0.3022,0.3174),(0.2877,0.3028,0.3180)]$} & {$[(0.0991,0.1043,0.1095),(0.1017,0.1070,0.1124)]$} \\
\hline & {$[(0.2866,0.3016,0.3167),(0.2877,0.3028,0.3180)]$} & {$[(0.2647,0.2787,0.2926),(0.2717,0.2860,0.3004)]$} \\
\hline & {$[(0.2756,0.2901,0.3046),(0.2762,0.2907,0.3053)]$} & {$[(0.1753,0.1845,0.1938),(0.1797,0.1892,0.1968)]$} \\
\hline
\end{tabular}

the well exploration field, and one organizer $\left(G_{3}\right)$ of oil company. Since the perspective of the decision makers may be not given the same importance, a weighted vector

$$
{ }^{k} \omega=\left({ }^{k} \widetilde{\omega_{1}}, k \widetilde{\omega_{2}}, \ldots,{ }^{k} \widetilde{\omega_{n}}\right)
$$

is introduced to denote the importance weight for the criteria regarding the opinion of the decision maker $G_{k}$ with $k=1,2,3$. Next, determine the weighted vector of criteria by virtue of fuzzy AHP, which is suitable for dealing with the uncertainty associated with the mapping of human judgment to a number by natural language. Following the fuzzy AHP approach provided in Section 2, for the purpose of weighting the criteria of refractured well selection, the factors and sub-factors are determined by the group decision makers as follows. The factors affecting refractured well selection are composed of the properties of objective thing (PO) and the productive features (PF), and the sub-factors consist of all the criteria of well 
Table 4: Local weights and pairwise comparison matrix of factors.

\begin{tabular}{lccc}
\hline Factors & PO & PF & Local weights for decision maker $G_{1}$ \\
\hline PO & $(1,1,1)$ & $(1,3 / 2,2)$ & $(0.4142,0.6000,0.8284)$ \\
PF & $(1 / 2,2 / 3,1)$ & $(1,1,1)$ & $(0.2929,0.4000,0.5858)$ \\
\hline Factors & PO & PF & Local weights for decision maker $G_{2}$ \\
\hline PO & $(1,1,1)$ & $(2 / 5,1 / 2,2 / 3)$ & $(0.2638,0.3333,0.4396)$ \\
PF & $(3 / 2,2,5 / 2)$ & $(1,1,1)$ & $(0.5108,0.6667,0.8514)$ \\
\hline Factors & PO & PF & Local weights for decision maker $G_{3}$ \\
\hline PO & $(1,1,1)$ & $(1,1,1)$ & $(0.5000,0.5000,0.5000)$ \\
PF & $(1,1,1)$ & $(1,1,1)$ & $(0.5000,0.5000,0.5000)$ \\
\hline
\end{tabular}

Table 5: Local weights and pairwise comparison matrix of subfactors belonging to PO.

\begin{tabular}{|c|c|c|c|c|c|c|}
\hline & $c 1$ & $c 2$ & $c 3$ & $c 4$ & $c 5$ & Local weights for $G_{1}$ \\
\hline$c 1$ & $(1,1,1)$ & $(3 / 2,2,5 / 2)$ & $(1,3 / 2,2)$ & $(1,3 / 2,2)$ & $(3 / 2,2,5 / 2)$ & $(0.1841,0.2984,0.4555)$ \\
\hline$c 2$ & $\begin{array}{c}(2 / 5,1 / 2 \\
2 / 3)\end{array}$ & $(1,1,1)$ & $(1 / 2,2 / 3,1)$ & $(1 / 2,2 / 3,1)$ & $(1,1,1)$ & $(0.0988,0.1423,0.2206)$ \\
\hline$c 3$ & $(1 / 2,2 / 3,1)$ & $(1,3 / 2,2)$ & $(1,1,1)$ & $(1,1,1)$ & $(1,3 / 2,2)$ & $(0.1363,0.2085,0.3157)$ \\
\hline$c 4$ & $(1 / 2,2 / 3,1)$ & $(1,3 / 2,2)$ & $(1,1,1)$ & $(1,1,1)$ & $(1,3 / 2,2)$ & $(0.1363,0.2085,0.3157)$ \\
\hline \multirow[t]{2}{*}{$c 5$} & $\begin{array}{c}(2 / 5,1 / 2 \\
2 / 3)\end{array}$ & $(1,1,1)$ & $(1 / 2,2 / 3,1)$ & $(1 / 2,2 / 3,1)$ & $(1,1,1)$ & $(0.0988,0.1423,0.2206)$ \\
\hline & $c 1$ & $c 2$ & $c 3$ & $c 4$ & $c 5$ & Local weights for $G_{2}$ \\
\hline$c 1$ & $(1,1,1)$ & $(1,3 / 2,2)$ & $(1 / 2,1,3 / 2)$ & $(1 / 2,1,3 / 2)$ & $(1,3 / 2,2)$ & $(0.1146,0.2285,0.3895)$ \\
\hline$c 2$ & $(1 / 2,2 / 3,1)$ & $(1,1,1)$ & $(2 / 5,1 / 2,2 / 3)$ & $(2 / 5,1 / 2,2 / 3)$ & $(1,1,1)$ & $(0.0912,0.1358,0.2134)$ \\
\hline$c 3$ & $(2 / 3,1,2)$ & $(3 / 2,2,5 / 2)$ & $(1,1,1)$ & $(1,1,1)$ & $(3 / 2,2,5 / 2)$ & $(0.1639,0.2564,0.4159)$ \\
\hline$c 4$ & $(2 / 3,1,2)$ & $(3 / 2,2,5 / 2)$ & $(1,1,1)$ & $(1,1,1)$ & $(1 / 2,1,3 / 2)$ & $(0.1316,0.2232,0.3755)$ \\
\hline \multirow[t]{2}{*}{$c 5$} & $(1 / 2,2 / 3,1)$ & $(1,1,1)$ & $(2 / 5,1 / 2,2 / 3)$ & $(2 / 3,1,2)$ & $(1,1,1)$ & $(0.1010,0.1560,0.2658)$ \\
\hline & $c 1$ & $c 2$ & $c 3$ & $c 4$ & $c 5$ & Local weights for $G_{3}$ \\
\hline$c 1$ & $(1,1,1)$ & $(2 / 7,1 / 3,2 / 5)$ & $(2,5 / 2,3)$ & $(2,5 / 2,3)$ & $(5 / 2,3,7 / 2)$ & $(0.1825,0.2467,0.3312)$ \\
\hline$c 2$ & $(5 / 2,3,7 / 2)$ & $(1,1,1)$ & $(5 / 2,3,7 / 2)$ & $(5 / 2,3,7 / 2)$ & $(5 / 2,3,7 / 2)$ & $(0.3080,0.4118,0.5436)$ \\
\hline$c 3$ & $\begin{array}{c}(1 / 3,2 / 5 \\
1 / 2)\end{array}$ & $(2 / 7,1 / 3,2 / 5)$ & $(1,1,1)$ & $(1,3 / 2,2)$ & $(1,3 / 2,2)$ & $(0.0925,0.1344,0.1908)$ \\
\hline$c 4$ & $\begin{array}{c}(1 / 3,2 / 5 \\
1 / 2)\end{array}$ & $(2 / 7,1 / 3,2 / 5)$ & $(1 / 2,2 / 3,1)$ & $(1,1,1)$ & $(1,1,1)$ & $(0.0805,0.1054,0.1446)$ \\
\hline$c 5$ & $\begin{array}{c}(2 / 7,1 / 3 \\
2 / 5)\end{array}$ & $(2 / 7,1 / 3,2 / 5)$ & $(1 / 2,2 / 3,1)$ & $(1,1,1)$ & $(1,1,1)$ & $(0.0780,0.1016,0.1383)$ \\
\hline
\end{tabular}

selection for refracturing, where the criteria $c 1, c 2, c 3, c 4$, and $c 5$ belong to $\mathrm{PO}$ and the criteria $c 6, c 7$, and $c 8$ belong to PF. Pairwise comparison matrices used to calculate weights for factors and sub-factors are formed by each decision member, respectively, see Tables 4, 5, 6, and 7 .

For two normalized triangular fuzzy numbers $A$ and $B$, its greatest value is $H=$ $(1,1,1)$. So, we can compare the size of $A$ and $B$ by comparing the distances $d(A, H)$ and $d(B, H)$. If it shows that distance from $A$ to $H$ is farther than distance from $B$ to $H$; that is, $d(A, H)>d(B, H)$, then we say $B$ is larger than $A$ or $B$ is more important than $A$; that is, 
Table 6: Local weights and pairwise comparison matrix of subfactors belonging to PF.

\begin{tabular}{ccccc}
\hline & $c 6$ & $c 7$ & $c 8$ & Local weights for $G_{1}$ \\
\hline$c 6$ & $(1,1,1)$ & $(1 / 2,2 / 3,1)$ & $(1 / 2,2 / 3,1)$ & $(0.1790,0.2500,0.3802)$ \\
$c 7$ & $(1,3 / 2,2)$ & $(1,1,1)$ & $(1,1,1)$ & $(0.2841,0.3750,0.4791)$ \\
$c 8$ & $(1,3 / 2,2)$ & $(1,1,1)$ & $(1,1,1)$ & $(0.2841,0.3750,0.4791)$ \\
\hline & $c 6$ & $c 7$ & $c 8$ & Local weights for $G_{2}$ \\
\hline$c 6$ & $(1,1,1)$ & $(2 / 3,1,2)$ & $(1 / 2,2 / 3,1)$ & $(0.1766,0.2809,0.5187)$ \\
$c 7$ & $(1 / 2,1,3 / 2)$ & $(1,1,1)$ & $(5 / 2,3,7 / 2)$ & $(0.2744,0.4638,0.7155)$ \\
$c 8$ & $(1,3 / 2,2)$ & $(2 / 7,1 / 3,2 / 5)$ & $(1,1,1)$ & $(0.1678,0.2552,0.3821)$ \\
\hline & $c 6$ & $c 7$ & $c 8$ & Local weights for $G_{3}$ \\
\hline$c 6$ & $(1,1,1)$ & $(1,3 / 2,2)$ & $(2 / 7,1 / 3,2 / 5)$ & $(0.1725,0.2281,0.3070)$ \\
$c 7$ & $(1 / 2,2 / 3,1 / 2)$ & $(1,1,1)$ & $(2 / 7,1 / 3,2 / 5)$ & $(0.1369,0.1741,0.1934)$ \\
$c 8$ & $(5 / 2,3,7 / 2)$ & $(5 / 2,3,7 / 2)$ & $(1,1,1)$ & $(0.4824,0.5978,0.7625)$ \\
\hline
\end{tabular}

Table 7: Computed global weights for sub-factors.

\begin{tabular}{lccc}
\hline Criteria & Decision maker $G_{1}$ & Decision maker $G_{2}$ & Decision maker $G_{3}$ \\
\hline$c 1$ & $(0.0763,0.1790,0.3774)$ & $(0.0302,0.0762,0.1710)$ & $(0.0913,0.1234,0.1656)$ \\
$c 2$ & $(0.0409,0.0854,0.1828)$ & $(0.0241,0.0453,0.0937)$ & $(0.1540,0.2059,0.2718)$ \\
$c 3$ & $(0.0565,0.1251,0.2616)$ & $(0.0432,0.0855,0.1826)$ & $(0.0462,0.0672,0.0954)$ \\
$c 4$ & $(0.0565,0.1251,0.2616)$ & $(0.0347,0.0744,0.1649)$ & $(0.0402,0.0527,0.0723)$ \\
$c 5$ & $(0.0409,0.0854,0.1828)$ & $(0.0267,0.0520,0.1167)$ & $(0.0390,0.0508,0.0692)$ \\
$c 6$ & $(0.0524,0.1000,0.2227)$ & $(0.0902,0.1873,0.4416)$ & $(0.0862,0.1141,0.1535)$ \\
$c 7$ & $(0.0832,0.1500,0.2806)$ & $(0.1401,0.3092,0.6091)$ & $(0.0685,0.0870,0.0967)$ \\
$c 8$ & $(0.0832,0.1500,0.2806)$ & $(0.0857,0.1702,0.3254)$ & $(0.2412,0.2989,0.3812)$ \\
\hline
\end{tabular}

$B>A$. Therefore, by Table 7 , the ordering for the criteria according to the importance weights given by each decision maker is the following:

$$
\begin{aligned}
& G_{1}: c 1>c 7=c 8>c 3=c 4>c 6>c 2=c 5 \\
& G_{2}: c 7>c 6>c 8>c 3>c 1>c 4>c 5>c 2 \\
& G_{3}: c 8>c 2>c 1>c 6>c 7>c 3>c 4>c 5 .
\end{aligned}
$$

It is shown that $G_{1}$ seeks to maximize the effective permeability $c 1$, which is one of the important parameters in evaluating reservoir. $G_{2}$ stress optimizing the productive features including formation pressure $c 7$, producing pressure drop $c 6$, and then oil production daily $c 8$. $G_{3}$ seeks to maximize the output of production $c 8$.

Next, the proposed fuzzy TOPSIS procedure is applied to determine final ranking for the alternatives. Taking decision maker 1 as an example, by using Tables 3 and 7, Step 2 
in Section 3 constructs a weighted fuzzy normalized decision matrix ${ }^{1} \widetilde{B}$ shown in Table 8 . Step 3 identifies the positive ideal solution ${ }^{1} S^{+}$and negative ideal solution ${ }^{1} S^{-}$as follows:

$$
\begin{aligned}
& { }^{1} S^{+}=\left(\begin{array}{ll}
{[(0.0307,0.0759,0.1679),} & (0.0319,0.0789,0.1747)], \\
{[(0.0189,0.0416,0.0934),} & (0.0213,0.0467,0.1050)], \\
{[(0.0171,0.0399,0.0876),} & (0.0185,0.0432,0.0949)], \\
{[(0.0118,0.0275,0.0603),} & (0.0124,0.0288,0.0633)], \\
{[(0.0012,0.0025,0.0057),} & (0.0012,0.0027,0.0060)], \\
{[(0.0239,0.0186,0.0434),} & (0.0095,0.0191,0.0447)], \\
{[(0.0300,0.0570,0.0890),} & (0.0239,0.0454,0.0892)],
\end{array}\right) \\
& { }^{1} S^{-}=\left(\begin{array}{cc}
{[(0.0005,0.0012,0.0027),} & (0.0007,0.0018,0.0040)], \\
{[(0.0034,0.0075,0.0168),} & (0.0043,0.0093,0.0210)] \\
{[(0.0114,0.0266,0.0584),} & (0.0128,0.0299,0.0657)] \\
{[(0.0171,0.0398,0.0874),} & (0.0177,0.0412,0.0904)], \\
{[(0.0173,0.0380,0.0854),} & (0.0183,0.0402,0.0903)], \\
{[(0.0198,0.0398,0.0930),} & (0.0205,0.0411,0.0961)] \\
{[(0.0082,0.0156,0.0307),} & (0.0191,0.0363,0.0714)]
\end{array}\right),
\end{aligned}
$$

where $J_{1}=\{c 1, c 2, c 3, c 7, c 8\}$ and $J_{2}=\{c 4, c 5, c 6\}$.

Steps 3, 4, and 5 in Section 3 calculate the distances ${ }^{1} d_{i}^{+},{ }^{1} d_{i}^{-}$and the relative closeness ${ }^{1} p\left(A_{i}\right)$ with $i=1, \ldots, 6$. And the results with the application of the proposed fuzzy TOPSIS for another decision makers $G_{2}$ and $G_{3}$ can be obtained by similar calculation. These results are shown in Table 9. The most promising alternative for refracturing measurement according to $G_{1}\left({ }^{1} p\left(A_{1}\right)=0.7150\right), G_{2}\left({ }^{2} p\left(A_{1}\right)=0.6382\right)$, and $G_{3}\left({ }^{3} p\left(A_{1}\right)=0.8103\right)$ is the alternative $A_{1}$, possibly due to the optimal relative closeness and higher performance ratings for the criteria $c 1, c 2$, and $c 8$. Moreover, these criteria are just stressed by the three decision makers. The second-best alternative may be $A_{3}$, which has higher performance ratings for the criteria $c 1, c 2$, and $c 8$. However, from the viewpoint of the cost criteria (that is to say, the less its value for cost criterion, the better the criterion), $A_{3}$ has higher cost criteria $c 4([50,51]), c 5([11.35,12]), c 6([12,13])$ than $A_{1}$ 's cost criteria $c 4([49,50]), c 5([6.48,6.5]), c 6([8.9,9.1])$. In addition, $A_{4}$ and $A_{5}$ are the most preferable ones in the view of three decision makers due to the suitable amount of performance ratings on benefit criteria. However, the alternative $A_{2}$ is considered the worst alternative, possibly due to its rather poor effective permeability $[0.2,0.3]$. From Table 2, the minimum and maximum for skin factor are presented by $A_{2}$ and $A_{3}$, respectively. Because skin factor is the least importance weight among all the alternatives for decision makers, $A_{2}$ remains a weak alternative. The latter discordance between $A_{2}$ and $A_{6}$ among decision makers might be explained by differences in various criteria, where $A_{2}$ has the lowest rating $[0.2,0.3]$ with respect to the criterion $c 1$, but $A_{6}$ has the lowest rating [4,4.5] with respect to the criterion $c 3$, the criteria $c 2, c 5, c 7$, and $c 8$ of alternative $A_{2}$ are superior to that of alternative $A_{6}$, and the criteria $c 4$ and $c 6$ of alternative $A_{6}$ are superior to that of alternative $A_{2}$. As a result of the discordances among opinions in group decision making, we shall further aggregate the obtained results from all the decision makers.

Next, suppose $\lambda=\left(\lambda_{1}, \lambda_{2}, \lambda_{3}\right)=(1 / 3,1 / 3,1 / 3)$ be the importance weight vector of decision makers, which means that all decision makers have the same importance. Then the 
Table 8: A weighted fuzzy normalized decision matrix.

\begin{tabular}{|c|c|}
\hline$c 1$ & $c 2$ \\
\hline $\begin{array}{l}A_{1} \quad[(0.0246,0.0607,0.1344),(0.0270,0.0668,0.1478)] \\
\end{array}$ & {$[(0.0189,0.0416,0.0934),(0.0213,0.0467,0.1050)]$} \\
\hline$A_{2} \quad[(0.0005,0.0012,0.0027),(0.0007,0.0018,0.0040)]$ & {$[(0.0108,0.0238,0.0535),(0.0117,0.0257,0.0577)]$} \\
\hline$A_{3} \quad[(0.0265,0.0655,0.1451),(0.0275,0.0680,0.1505)]$ & {$[(0.0104,0.0229,0.0514),(0.0113,0.0248,0.0556)]$} \\
\hline$A_{4} \quad[(0.0111,0.0273,0.0605),(0.0123,0.0303,0.0672)]$ & {$[(0.0068,0.0149,0.0336),(0.0080,0.0175,0.0394)]$} \\
\hline$A_{5}[(0.0307,0.0759,0.1679),(0.0319,0.0789,0.1747)]$ & {$[(0.0034,0.0075,0.0168),(0.0043,0.0093,0.0210)]$} \\
\hline$A_{6} \quad[(0.0098,0.0243,0.0537),(0.0111,0.0273,0.0605)]$ & {$[(0.0055,0.0121,0.0273),(0.0064,0.0140,0.0315)]$} \\
\hline$c 3$ & $c 4$ \\
\hline $\begin{array}{l}A_{1} \quad[(0.0157,0.0366,0.0803),(0.0171,0.0399,0.0876)] \\
\end{array}$ & {$[(0.0144,0.0336,0.0738),(0.0147,0.0343,0.0754)]$} \\
\hline$A_{2} \quad[(0.0157,0.0366,0.0803),(0.0171,0.0399,0.0876)]$ & {$[(0.0168,0.0391,0.0859),(0.0174,0.0405,0.0889)]$} \\
\hline$A_{3} \quad[(0.0137,0.0319,0.0701),(0.0143,0.0332,0.0730)]$ & {$[(0.0147,0.0343,0.0754),(0.0150,0.0350,0.0769)]$} \\
\hline$A_{4} \quad[(0.0137,0.0319,0.0701),(0.0171,0.0399,0.0876)]$ & {$[(0.0162,0.0377,0.0829),(0.0165,0.0384,0.0844)]$} \\
\hline$A_{5} \quad[(0.0171,0.0399,0.0876),(0.0185,0.0432,0.0949)]$ & {$[(0.0171,0.0398,0.0874),(0.0177,0.0412,0.0904)]$} \\
\hline$A_{6} \quad[(0.0114,0.0266,0.0584),(0.0128,0.0299,0.0657)]$ & {$[(0.0118,0.0275,0.0603),(0.0124,0.0288,0.0633)]$} \\
\hline$c 5$ & c6 \\
\hline$A_{1} \quad[(0.0099,0.0217,0.0488),(0.0099,0.0218,0.0489)]$ & {$[(0.0118,0.0236,0.0552),(0.0120,0.0241,0.0564)]$} \\
\hline$A_{2} \quad[(0.0012,0.0025,0.0057),(0.0012,0.0027,0.0060)]$ & {$[(0.0131,0.0263,0.0614),(0.0132,0.0265,0.0620)]$} \\
\hline$A_{3} \quad[(0.0173,0.0380,0.0854),(0.0183,0.0402,0.0903)]$ & {$[(0.0158,0.0318,0.0744),(0.0172,0.0345,0.0806)]$} \\
\hline$A_{4} \quad[(0.0142,0.0312,0.0701),(0.0145,0.0318,0.0715)]$ & {$[(0.0092,0.0186,0.0434),(0.0095,0.0191,0.0447)]$} \\
\hline$A_{5} \quad[(0.0034,0.0075,0.0169),(0.0038,0.0084,0.0188)]$ & {$[(0.0198,0.0398,0.0930),(0.0205,0.0411,0.0961)]$} \\
\hline$A_{6} \quad[(0.0108,0.0238,0.0536),(0.0111,0.0244,0.0549)]$ & {$[(0.0125,0.0252,0.0589),(0.0127,0.0255,0.0595)]$} \\
\hline$c 7$ & $c 8$ \\
\hline$A_{1} \quad[(0.0190,0.0360,0.0707),(0.0191,0.0363,0.0714)]$ & {$[(0.0300,0.0570,0.1120),(0.0305,0.0579,0.1136)]$} \\
\hline$A_{2} \quad[(0.0238,0.0452,0.0889),(0.0239,0.0454,0.0892)]$ & {$[(0.0222,0.0422,0.0829),(0.0226,0.0429,0.0843)]$} \\
\hline$A_{3} \quad[(0.0227,0.0432,0.0848),(0.0229,0.0434,0.0853)]$ & {$[(0.0300,0.0569,0.1117),(0.0306,0.0581,0.1142)]$} \\
\hline$A_{4} \quad[(0.0239,0.0453,0.0890),(0.0239,0.0454,0.0892)]$ & {$[(0.0082,0.0156,0.0307),(0.0085,0.0161,0.0315)]$} \\
\hline$A_{5} \quad[(0.0238,0.0452,0.0889),(0.0239,0.0454,0.0892)]$ & {$[(0.0220,0.0418,0.0821),(0.0226,0.0429,0.0843)]$} \\
\hline$A_{6} \quad[(0.0229,0.0435,0.0855),(0.0230,0.0436,0.0857)]$ & {$[(0.0146,0.0277,0.0544),(0.0150,0.0284,0.0557)]$} \\
\hline
\end{tabular}

Table 9: Application of the fuzzy TOPSIS for decision makers with weights.

\begin{tabular}{lcccccccccccc}
\hline Alt. & ${ }^{1} d_{i}^{+}$ & ${ }^{1} d_{i}^{-}$ & ${ }^{1} p\left(A_{i}\right)$ & Rank & ${ }^{2} d_{i}^{+}$ & ${ }^{2} d_{i}^{-}$ & ${ }^{2} p\left(A_{i}\right)$ & Rank & ${ }^{3} d_{i}^{+}$ & ${ }^{3} d_{i}^{-}$ & ${ }^{3} p\left(A_{i}\right)$ & Rank \\
\hline$A_{1}$ & 0.0800 & 0.2006 & 0.7150 & 1 & 0.0754 & 0.1330 & 0.6382 & 1 & 0.0392 & 0.1674 & 0.8103 & 1 \\
$A_{2}$ & 0.1882 & 0.0759 & 0.2873 & 6 & 0.1213 & 0.0707 & 0.3683 & 6 & 0.1549 & 0.0906 & 0.3690 & 5 \\
$A_{3}$ & 0.1436 & 0.2141 & 0.5985 & 2 & 0.1182 & 0.1492 & 0.5580 & 2 & 0.1116 & 0.1394 & 0.5553 & 2 \\
$A_{4}$ & 0.2285 & 0.1693 & 0.4256 & 4 & 0.1558 & 0.1272 & 0.4496 & 4 & 0.2233 & 0.1557 & 0.4109 & 4 \\
$A_{5}$ & 0.1292 & 0.1854 & 0.5893 & 3 & 0.1290 & 0.1504 & 0.5384 & 3 & 0.1603 & 0.1244 & 0.4371 & 3 \\
$A_{6}$ & 0.2190 & 0.1420 & 0.3934 & 5 & 0.1574 & 0.1203 & 0.4331 & 5 & 0.2119 & 0.1235 & 0.3683 & 6 \\
\hline
\end{tabular}

weighted relative closeness matrix is calculated and shown in Table 10. The group positive ideal solutions and group negative ideal solutions are also calculated by utilizing TOPSIS. Finally Step 9 in Section 3 presents the final ranking for refractured well selection. According to the preference order of $\delta_{G}\left(A_{i}\right)$, the final ranking of these alternatives is $A_{1}>A_{3}>A_{5}>$ $A_{4}>A_{6}>A_{2}$. It shows that alternative $A_{1}$ is the best one and $A_{3}$ is the second by Table 10, which could be explained mainly by sufficient oil production daily and effective permeability. Indeed these criteria are more attractive for decision makers. 
Table 10: The weighted relative closeness matrix, group positive (negative) ideal solution, and ranking.

\begin{tabular}{lccccccc}
\hline Alternatives & $(1 / 3) \cdot{ }^{1} p\left(A_{i}\right)$ & $(1 / 3) \cdot{ }^{2} p\left(A_{i}\right)$ & $(1 / 3) \cdot{ }^{3} p\left(A_{i}\right)$ & $d_{G_{i}}^{+}$ & $d_{G_{i}}^{-}$ & $\delta_{G}$ & Ranking \\
\hline$A_{1}$ & 0.2383 & 0.2127 & 0.2701 & 0 & 0.2239 & 1.0000 & 1 \\
$A_{2}$ & 0.0958 & 0.1228 & 0.1230 & 0.2237 & 0.0002 & 0.0010 & 6 \\
$A_{3}$ & 0.1995 & 0.1860 & 0.1851 & 0.0972 & 0.1365 & 0.5842 & 2 \\
$A_{4}$ & 0.1419 & 0.1499 & 0.1370 & 0.1760 & 0.0553 & 0.2392 & 4 \\
$A_{5}$ & 0.1964 & 0.1795 & 0.1457 & 0.1354 & 0.1178 & 0.4652 & 3 \\
$A_{6}$ & 0.1311 & 0.1444 & 0.1228 & 0.1946 & 0.0414 & 0.1756 & 5 \\
\hline
\end{tabular}

Table 11: The weighted relative closeness matrix by using importance weight $\lambda=(0.2,0.2,0.6)$ and ranking.

\begin{tabular}{lccccccc}
\hline Alternatives & $0.2 \cdot{ }^{1} p\left(A_{i}\right)$ & $0.2 \cdot{ }^{2} p\left(A_{i}\right)$ & $0.6 \cdot{ }^{3} p\left(A_{i}\right)$ & $d_{G_{i}}^{+}$ & $d_{G_{i}}$ & $\delta_{G}$ & Ranking \\
\hline$A_{1}$ & 0.1430 & 0.1276 & 0.4862 & 0 & 0.2838 & 1.0000 & 1 \\
$A_{2}$ & 0.0575 & 0.0737 & 0.2214 & 0.2834 & 0.0004 & 0.0015 & 6 \\
$A_{3}$ & 0.1197 & 0.1116 & 0.3332 & 0.1556 & 0.1338 & 0.4623 & 2 \\
$A_{4}$ & 0.0851 & 0.0899 & 0.2465 & 0.2494 & 0.0410 & 0.1412 & 4 \\
$A_{5}$ & 0.1179 & 0.1077 & 0.2623 & 0.2262 & 0.0807 & 0.2629 & 3 \\
$A_{6}$ & 0.0787 & 0.0866 & 0.2210 & 0.2760 & 0.0249 & 0.0827 & 5 \\
\hline
\end{tabular}

Table 12: The increasing daily oil production of the alternatives after refracturing.

\begin{tabular}{lcccccc}
\hline Alternatives & $A_{1}$ & $A_{2}$ & $A_{3}$ & $A_{4}$ & $A_{5}$ & $A_{6}$ \\
\hline The increasing oil production $(\mathrm{t} / \mathrm{d})$ & 10.6 & 1.3 & 8.0 & 5.1 & 7.8 & 1.6 \\
\hline
\end{tabular}

By changing the importance weights of the group decision makers, the ranking of the alternatives may be modified. Now, by virtue of the TOPSIS, another different important weight vector $\mathcal{\lambda}=(0.2,0.2,0.6)$ is chosen to calculate the weighted relative closeness matrix, group positive ideal solution, and group negative ideal solution, and to determine the final ranking for refractured well selection in Table 11. The scenario pays the most of attention to the organizer of oil company and leave two experts from the well exploration field equally important.

After two months for refracturing, the increasing daily oil production of these alternatives is presented in Table 12. Therefore, according to the decreasing order of the increasing oil production daily, the final ranking of these alternatives is $A_{1}>A_{3}>A_{5}>$ $A_{4}>A_{6}>A_{2}$, which reaches an agreement on the results of the proposed methodology. It is proven by practice that the proposed method is of great reliability and suitable for solving refractured well-selection problem.

If we utilize the AHP [24] and TOPSIS [2] to evaluate the alternatives for refracturing measurement, the preference order of alternatives may not be in accordance with the result obtained from the proposed fuzzy methodology. In fact, suppose the input data be the medium of every element from Table 2, and global weights for criteria with respect to each decision maker are calculated as shown in Table 13.

Then the TOPSIS is applied to rank the alternatives on a basis of input weights by AHP. The corresponding results are shown in Table 14. When the group decision makers have the same importance; that is, $\lambda=(1 / 3,1 / 3,1 / 3)$ is assigned to the importance weight vector of decision makers, the preference order determined by AHP and TOPSIS methodology is $A_{1}>A_{3}>A_{5}>A_{2}>A_{6}>A_{4}$. If $\lambda=(0.2,0.2,0.6)$ is assigned to the importance weight vector 
Table 13: Computed global weights for criteria through AHP.

\begin{tabular}{lcccccccc}
\hline Criteria & $c 1$ & $c 2$ & $c 3$ & $c 4$ & $c 5$ & $c 6$ & $c 7$ & $c 8$ \\
\hline Decision maker $G_{1}$ & 0.180 & 0.085 & 0.125 & 0.125 & 0.085 & 0.100 & 0.150 & 0.150 \\
Decision maker $G_{2}$ & 0.076 & 0.045 & 0.086 & 0.074 & 0.052 & 0.187 & 0.310 & 0.170 \\
Decision maker $G_{3}$ & 0.123 & 0.206 & 0.067 & 0.053 & 0.051 & 0.114 & 0.087 & 0.299 \\
\hline
\end{tabular}

Table 14: Application of the TOPSIS to rank the alternatives.

\begin{tabular}{lcccccc}
\hline Alternatives & $A_{1}$ & $A_{2}$ & $A_{3}$ & $A_{4}$ & $A_{5}$ & $A_{6}$ \\
\hline${ }_{1} p\left(A_{i}\right)$ & 0.7662 & 0.3905 & 0.6307 & 0.3350 & 0.6537 & 0.3435 \\
Ranking & 1 & 4 & 3 & 6 & 2 & 5 \\
${ }^{2} p\left(A_{i}\right)$ & 0.7250 & 0.5528 & 0.6107 & 0.4519 & 0.5190 & 0.4453 \\
Ranking & 1 & 3 & 2 & 5 & 4 & 6 \\
${ }^{3} p\left(A_{i}\right)$ & 0.8836 & 0.4833 & 0.6421 & 0.2471 & 0.4484 & 0.2677 \\
Ranking & 1 & 3 & 2 & 6 & 4 & 5 \\
$\delta_{G}$ with $\lambda=(0.2,0.2,0.6)$ & 1.0000 & 0.3614 & 0.6230 & 0.0033 & 0.3411 & 0.0315 \\
Group ranking & 1 & 3 & 2 & 6 & 4 & 5 \\
$\delta_{G}$ with $\lambda=(1 / 3,1 / 3,1 / 3)$ & 1.0000 & 0.3156 & 0.6347 & 0.0080 & 0.4372 & 0.0272 \\
Group ranking & 1 & 4 & 2 & 6 & 3 & 5 \\
\hline
\end{tabular}

of decision makers, then the preference order is $A_{1}>A_{3}>A_{2}>A_{5}>A_{6}>A_{4}$. It shows that the results are not in accordance with the field study, although the best and second-best alternatives are the same as those through the field study.

The AHP and TOPSIS methods are regarded as viable approaches in solving a decision problem when precise performance ratings are available. However, it has the constraints in the conditions of inaccurate or vague performance ratings. For this case study, the application of fuzzy AHP and fuzzy TOPSIS methodology can copy with the well-selection problem for refracturing measurement effectively.

\section{Conclusions}

When considering the fact that, in many cases, multicriteria decision-making problems are affected by uncertainty and taking into account the subjective preferences of the group decision makers, we introduce interval-typed fuzzy numbers to express the values of these criteria. Therefore, in this paper, a new model for multicriteria decision-making problem is constructed by integrating fuzzy AHP with fuzzy TOPSIS, where the fuzzy AHP is used to analyze the structure of the selection problem and to determine weights of the criteria in the form of triangular fuzzy numbers, and fuzzy TOPSIS with interval-typed triangular fuzzy numbers is proposed to determine final ranking for refractured well selection. Furthermore, the algorithm allows finding the best alternatives.

From the field study, the proposed method is proven to be of great reliability and significance for well selection during refracturing treatment. Since the computation processes are straightforward and understandable, it is believed that the method can be applied to solve other complex and fuzzy MCGDM problems with a more amount of alternatives, criteria, and group decision makers. 


\section{Acknowledgment}

This work is supported by research on the model and the method of parameter identification in reservoir simulation under Grant PLN1121.

\section{References}

[1] S. T Chen and C. L. Hwang, Fuzzy Multiple Attribute Decision Making: Methods and Applications, Springer, Berlin, Germany, 1992.

[2] C. L. Hwang and K. Yoon, Multiple Attribute Decision Making Methods and Applications, Springer, Berlin, Germany, 1981.

[3] L. Duckstein and S. Opricovic, "Multiobjective optimization in river basin development," Water Resources Research, vol. 16, no. 1, pp. 14-20, 1980.

[4] L. Baležentienè and A. Užupis, "Multi-criteria optimization for mitigation model of greenhouse gas emissions from abandoned grassland," Journal of Food, Agriculture E Environment, vol. 10, pp. 859-865, 2012.

[5] F. Ye, "An extended TOPSIS method with interval-valued intuitionistic fuzzy numbers for virtual enterprise partner selection," Expert Systems with Applications, vol. 37, pp. 7050-7055, 2010.

[6] M. P. Amiri, "Project selection for oil-fields development by using the AHP and fuzzy TOPSIS methods," Expert Systems with Applications, vol. 37, pp. 6218-6224, 2010.

[7] P. K. Dey, "Integrated project evaluation and selection using multiple-attribute decision-making technique," International Journal of Production Economics, vol. 103, no. 1, pp. 90-103, 2006.

[8] B. Ashtiani, F. Haghighirad, A. Makui, and G. A. Montazer, "Extension of fuzzy TOPSIS method based on interval-valued fuzzy sets," Applied Soft Computing Journal, vol. 9, no. 2, pp. 457-461, 2009.

[9] A. Baležentis and T. Baležentis, "A novel method for group multi-attribute decision making with two-tuple linguistic computing: supplier evaluation under uncertainty," Economic Computation and Economic Cybernetics Studies and Research, vol. 45, no. 4, pp. 5-30, 2011.

[10] A. Guitouni and J. M. Martel, "Tentative guidelines to help choosing an appropriate MCDA method," European Journal of Operational Research, vol. 109, no. 2, pp. 501-521, 1998.

[11] M. S. Kuo and G. S. Liang, "A soft computing method of performance evaluation with MCDM based on interval-valued fuzzy numbers," Applied Soft Computing, vol. 12, pp. 476-485, 2012.

[12] S. Opricovic, Multicriteria Optimization of Civil Engineering Systems, Faculy of Civil Engineering, Belgrade, Serbia, 1998.

[13] S. Opricovic and G. H. Tzeng, "Compromise solution by MCDM methods: a comparative analysis of VIKOR and TOPSIS," European Journal of Operational Research, vol. 156, no. 2, pp. 445-455, 2004.

[14] K. Peniwati, "Criteria for evaluating group decision-making methods," Mathematical and Computer Modelling, vol. 46, no. 7-8, pp. 935-947, 2007.

[15] D. Bouyssou, "Some remarks on the notion of compensation in MCDM," European Journal of Operational Research, vol. 26, no. 1, pp. 150-160, 1986.

[16] Y. J. Lai, T. Y. Liu, and C. L. Hwang, "TOPSIS for MODM," European Journal of Operational Research, vol. 76, no. 3, pp. 486-500, 1994.

[17] L. A. Zadeh, "Fuzzy sets," Information and Computation, vol. 8, pp. 338-353, 1965.

[18] R. E. Bellman and L. A. Zadeh, "Decision-making in a fuzzy environment," Management Science, vol. 17, pp. 141-164, 1970.

[19] C. T. Chen, "Extensions of the TOPSIS for group decision-making under fuzzy environment," Fuzzy Sets and Systems, vol. 114, no. 1, pp. 1-9, 2000.

[20] G. R. Jahanshahloo, F. H. Lotfi, and M. Izadikhah, "An algorithmic method to extend TOPSIS for decision-making problems with interval data," Applied Mathematics and Computation, vol. 175, no. 2, pp. 1375-1384, 2006.

[21] L. Baležentienè and E. Klimas, "Multi-criteria evaluation of new humic fertilizers effectiveness and optimal rate on a basis of TOPSIS method," Journal of Food, Agriculture E Environment, vol. 9, pp. 465-471, 2011.

[22] F. Wei-Guo and Z. Hong, "A multi-attribute group decision-making method approaching to group ideal solution," in Proceedings of IEEE International Conference on Grey Systems and Intelligent Services (GSIS '07), pp. 815-819, November 2007.

[23] R. A. Krohling and V. C. Campanharo, "Fuzzy TOPSIS for group decision making: a case study for accidents with oil spill in the sea," Expert Systems with Applications, vol. 38, no. 4, pp. 4190-4197, 2011.

[24] T. L. Saaty, The Analytic Hierarchy Process, McGraw-Hill, New York, NY, USA, 1980. 
[25] M. Dağdeviren and I. Yüksel, "Developing a fuzzy analytic hierarchy process (AHP) model for behavior-based safety management," Information Sciences, vol. 178, no. 6, pp. 1717-1733, 2008.

[26] S. M. Miri Lavasani, Z. Yang, J. Finlay, and J. Wang, "Fuzzy risk assessment of oil and gas offshore wells," Process Safety and Environmental Protection, vol. 89, pp. 277-294, 2011.

[27] Y. B. Ju and A. H. Wang, "Emergency alternative evaluation under group decision makers: a method of incorporating DS/AHP with extended TOPSIS," Expert Systems with Applications, vol. 39, pp. 13151323, 2012.

[28] T. L. Saaty and L. T. Tran, "On the invalidity of fuzzifying numerical judgments in the analytic hierarchy process," Mathematical and Computer Modelling, vol. 46, no. 7-8, pp. 962-975, 2007.

[29] C. C. Sun, "A performance evaluation model by integrating fuzzy AHP and fuzzy TOPSIS methods," Expert Systems with Applications, vol. 37, no. 12, pp. 7745-7754, 2010.

[30] A. T. Gumus, "Evaluation of hazardous waste transportation firms by using a two step fuzzy-AHP and TOPSIS methodology," Expert Systems with Applications, vol. 36, no. 2, pp. 4067-4074, 2009.

[31] F. Torfi, R. Z. Farahani, and S. Rezapour, "Fuzzy AHP to determine the relative weights of evaluation criteria and Fuzzy TOPSIS to rank the alternatives," Applied Soft Computing Journal, vol. 10, no. 2, pp. 520-528, 2010.

[32] G. Büyüközkan and G. Cifci, "A combined fuzzy AHP and fuzzy TOPSIS based strategic analysis of electronic service quality in healthcare industry," Expert Systems with Applications, vol. 39, pp. 23412354, 2012.

[33] T.-Y. Chen and C.-Y. Tsao, "The interval-valued fuzzy TOPSIS method and experimental analysis," Fuzzy Sets and Systems, vol. 159, no. 11, pp. 1410-1428, 2008.

[34] P. Liu, "A weighted aggregation operators multi-attribute group decision-making method based on interval-valued trapezoidal fuzzy numbers," Expert Systems with Applications, vol. 38, no. 1, pp. 1053 1060, 2011.

[35] P. Liu, "An extended TOPSIS method for multiple attribute group decision making based on generalized interval-valued trapezoidal fuzzy numbers," Informatica, vol. 35, no. 2, pp. 185-196, 2011.

[36] P. Liu and F. Jin, "A multi-attribute group decision-making method based on weighted geometric aggragation operators of interval-valued trapezoidal fuzzy numbers," Applied Mathematical Modelling, vol. 36, pp. 2498-2509, 2012.

[37] G. Wang and X. Li, "Correlation and information energy of interval-valued fuzzy numbers," Fuzzy Sets and Systems, vol. 103, no. 1, pp. 169-175, 1999.

[38] S. H. Wei and S. M. Chen, "Fuzzy risk analysis based on interval-valued fuzzy numbers," Expert Systems with Applications, vol. 36, no. 2, pp. 2285-2299, 2009.

[39] R.-C. Tsaur, "Decision risk analysis for an interval TOPSIS method," Applied Mathematics and Computation, vol. 218, no. 8, pp. 4295-4304, 2011.

[40] C. Kahraman, T. Ertay, and G. Büyüközkan, "A fuzzy optimization model for QFD planning process using analytic network approach," European Journal of Operational Research, vol. 171, no. 2, pp. 390-411, 2006.

[41] E. Tolga, M. L. Demircan, and C. Kahraman, “Operating system selection using fuzzy replacement analysis and analytic hierarchy process," International Journal of Production Economics, vol. 97, no. 1, pp. 89-117, 2005.

[42] L. Mikhailov, "A fuzzy approach to deriving priorities from interval pairwise comparison judgements," European Journal of Operational Research, vol. 159, no. 3, pp. 687-704, 2004.

[43] M. T. Tang, G. H. Tzeng, and S. W. Wang, "A hierarchy fuzzy MCDM method for studying electronic marketing strategies in the information service industry," Journal of International Information Management, vol. 8, pp. 1-22, 2000. 


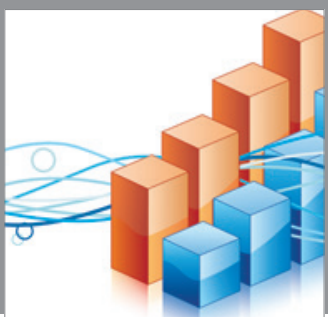

Advances in

Operations Research

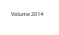

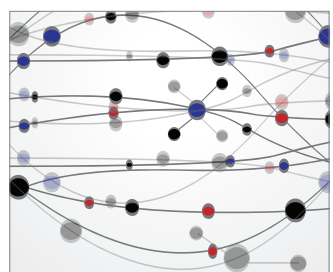

\section{The Scientific} World Journal
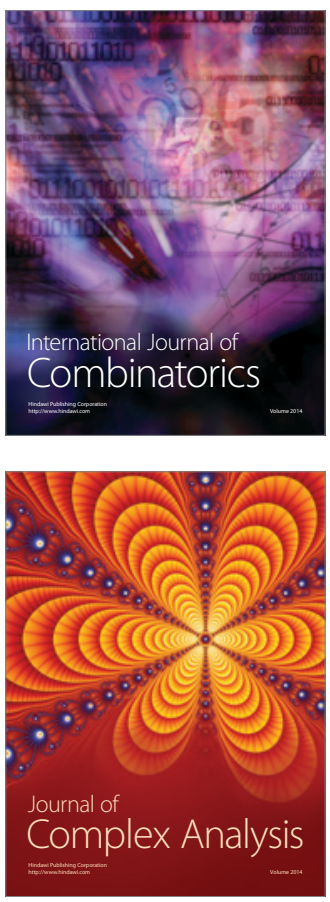

International Journal of

Mathematics and

Mathematical

Sciences
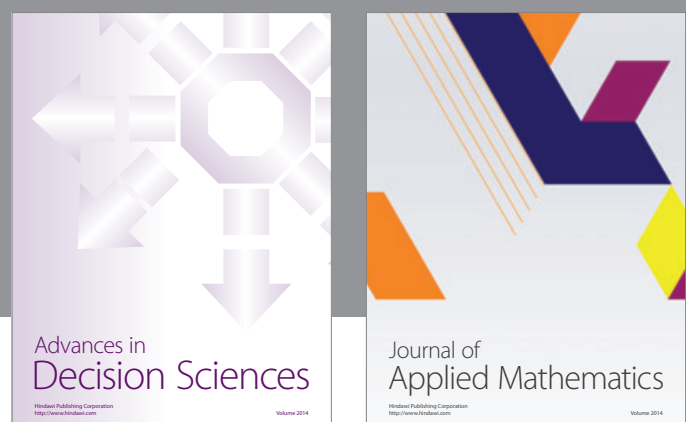

Journal of

Applied Mathematics
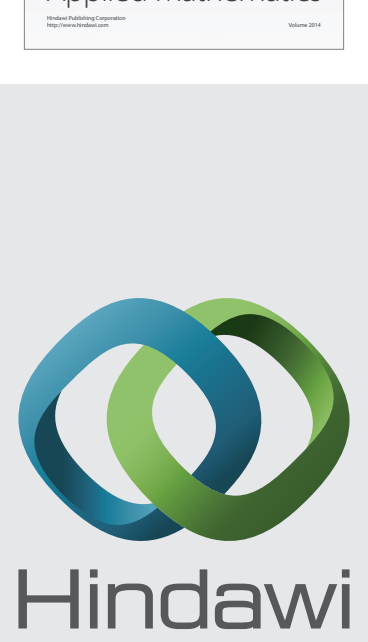

Submit your manuscripts at http://www.hindawi.com
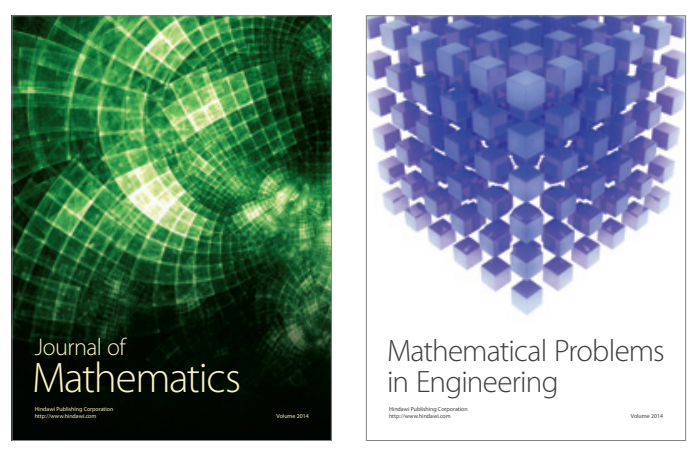

Mathematical Problems in Engineering
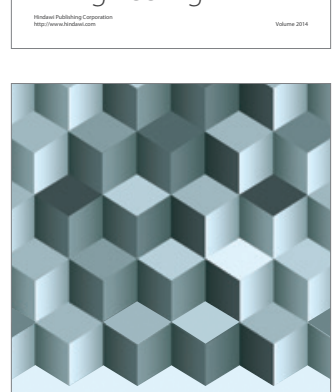

Journal of

Function Spaces
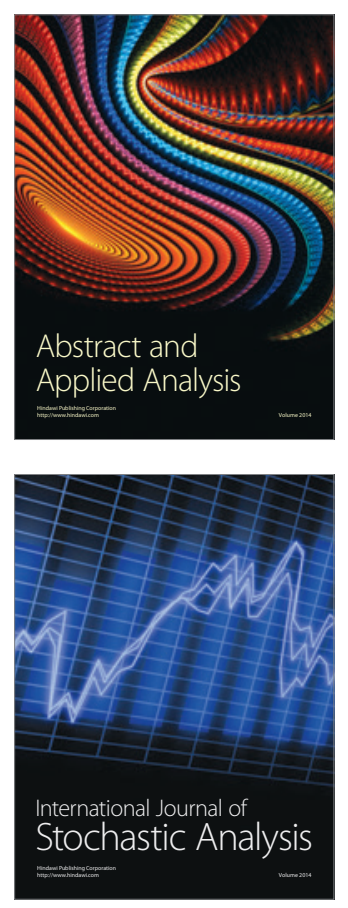

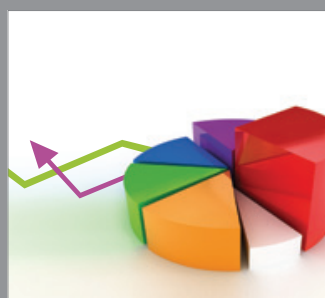

ournal of

Probability and Statistics

Promensencen
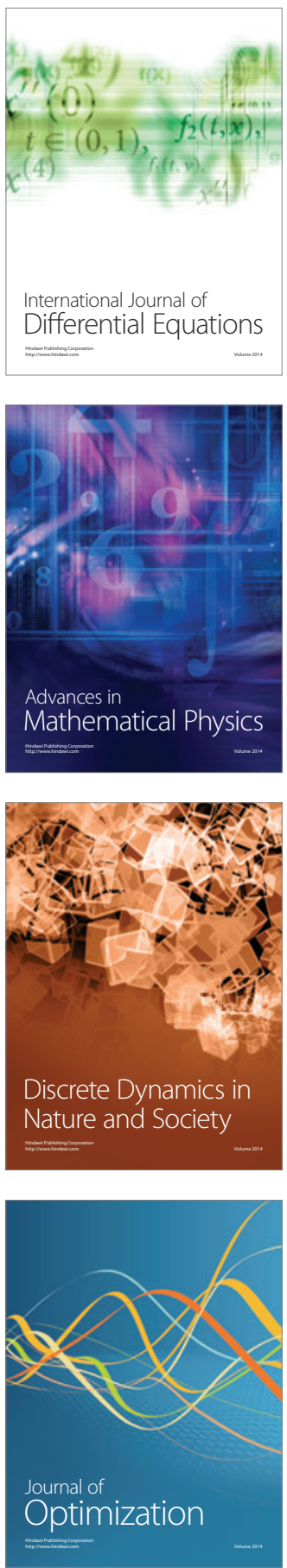